\title{
Streptomyces yunnanensis sp. nov., a mesophile from soils in Yunnan, China
}

Correspondence

Cheng-Lin Jiang

lihxu@ynu.edu.cn

\author{
Qi Zhang, Wen-Jun Li, Xiao-Long Cui, Ming-Gang Li, Li-Hua Xu and \\ Cheng-Lin Jiang
}

The Key Laboratory for Microbial Resources of Ministry of Education, PR China, Yunnan
Institute of Microbiology, Yunnan University, Kunming, Yunnan 650091, PR China

\begin{abstract}
A strain was isolated from red soil from the suburb of Kunming in Yunnan, China, during the screening of agricultural antibiotics which prevented and cured wheat-stem rust. This isolate, designated YIM 41004 ${ }^{\top}$ (=CGMCC $4.1004^{\top}=$ DSM $41793^{\top}$ ), was identified by a polyphasic approach. The test results suggested that this strain was clearly assigned to the genus Streptomyces and found to be marginally close to Williams cluster 32 based on the morphological and physiological data. The almost-complete $16 \mathrm{~S}$ rRNA gene sequence of the strain was determined and compared with those of representative streptomycetes. The phylogenetic tree confirmed its membership in the genus Streptomyces and demonstrated that this strain represented a separate phyletic line in a clade encompassed by streptomycetes within cluster 32 . Based on the polyphasic evidence, it is therefore proposed that strain YIM $41004^{\top}$ should be classified as Streptomyces yunnanensis sp. nov.
\end{abstract}

\section{INTRODUCTION}

The numerical taxonomic study of the genus Streptomyces by Williams et al. (1983) and the Streptomyces chapter in vol. 4 of Bergey's Manual of Systematic Bacteriology (Williams etal., 1989) delineated the Streptomyces violaceusniger cluster in terms of morphology for strains having grey, roughsurfaced spores in spiral chains, which encompassed S. violaceusniger, several Streptomyces hygroscopicus strains, Streptomyces sparsogenes and Streptomyces melanosporofaciens. A study of levels of DNA relatedness among strains of $S$. violaceusniger and other related taxa belonging to the S. violaceusniger cluster by Williams et al. $(1983,1989)$ demonstrated that the Streptomyces violaceusniger phenotypic cluster is heterogeneous in DNA relatedness among strains at a level of $>70 \%$, and strains in this cluster should be considered to be four distinct species, S. melanosporofaciens, S. sparsogenes, S. violaceusniger and S. hygroscopicus (Streptomyces endus was assigned as a subjective synonym in the revised description of S. hygroscopicus) (Labeda \& Lyons, 1991). A numerical classification, using miniaturized physiological tests, of the genera Streptomyces and Streptoverticillium by Kämpfer et al. (1991) showed that the distinct species described by Labeda \& Lyons (1991) in Williams cluster 32 were distributed into clusters $10,41,51$, 53, 54 and 85.

In the course of screening agricultural antibiotics that

Abbreviation: ISP, International Streptomyces Project.

The GenBank/EMBL/DDBJ accession number for the partial $16 \mathrm{~S}$ rDNA sequence of strain YIM $41004^{\top}$ is AF346818. prevent and cure wheat-stem rust, strain YIM $41004^{\mathrm{T}}$ was isolated from soil samples in Yunnan. It produces the antifungal agent cycloheximide. It is morphologically and physiologically similar to strains assigned to the Streptomyces violaceusniger cluster (Williams et al., 1983, 1989). The taxonomic results are reported in this paper.

\section{METHODS}

Organism. Strain YIM $41004^{\mathrm{T}}$ was isolated from the red soil of suburb of Kunming of Yunnan, China. The strain was maintained by cultivation on $38^{\#}$ agar medium that contained (per litre) $4 \mathrm{~g}$ glucose, $4 \mathrm{~g}$ yeast extract, $5 \mathrm{~g}$ malt extract and vitamin/amino acid mixture $\left(1 \mathrm{mg}\right.$ each of vitamin $\mathrm{B}_{1}$, vitamin $\mathrm{B}_{2}$, vitamin $\mathrm{B}_{6}$, biotin, nicotinic acid and phenylalanine, and $0.3 \mathrm{~g}$ alanine), with $\mathrm{pH}$ adjusted to $7 \cdot 2$, and incubated at $25-30{ }^{\circ} \mathrm{C}$ for $7-15$ days. The effect of temperature on growth rate was determined on $38^{\#}$ agar at 24$32{ }^{\circ} \mathrm{C}$ at intervals of $2{ }^{\circ} \mathrm{C}$; optimum growth was at $28^{\circ} \mathrm{C}$.

Phenotypic characterization. The medium used for morphological studies was yeast extract-malt extract agar (International Streptomyces Project medium no. 2, ISP 2) (Shirling \& Gottlieb, 1966) and the incubation time of the pure culture was 7-15 days at $28-30{ }^{\circ} \mathrm{C}$. Morphological observations were made by using optical and electron microscopy (model EPMA-8705). Cultural and physiological characteristics of strain YIM $41004^{\mathrm{T}}$ were determined according to the methods proposed by Shirling \& Gottlieb (1966) and Williams et al. (1983). Colour determinations were made by comparing the cultures with colour chips from the ISCC-NBS Color Charts Standard Sample No. 2106 (Kelly, 1964).

Chemotaxonomy. Cell wall was purified and analysed by the methods of Lechevalier \& Lechevalier (1980). The procedures of Becker et al. (1964) and Lechevalier \& Lechevalier (1980) were used for analyses of whole-cell chemical compositions. 
165 rDNA sequencing. The chromosomal DNA of strain YIM $41004^{\mathrm{T}}$ was isolated according to the procedure described by Hopwood et al. (1985). 16S rDNA was amplified by PCR using a PCR kit (Sino-American Biotechnology, Beijing), primer A 8-27f (5'-CCGTCGACGAGCTC AGAGTTTGATCCTGGCTCAG-3') and primer B 1523-1504r (5'-CCCGGGTACCAAGCTT AAGGAGGTGATCCAGCCGCA-3') (primers are in bold according to the Escherichia coli numbering system of Brosius et al., 1978). The conditions used for thermal cycling were as the follows: denaturation at $95{ }^{\circ} \mathrm{C}$ for 5 min followed by 35 cycles consisting of denaturation at $95^{\circ} \mathrm{C}$ for $1 \mathrm{~min}$, primer annealing at $56^{\circ} \mathrm{C}$ for $1 \mathrm{~min}$, and primer extention at $72{ }^{\circ} \mathrm{C}$ for $3 \mathrm{~min}$. At the end of the cycles, the reaction mixture was kept at $72{ }^{\circ} \mathrm{C}$ for $5 \mathrm{~min}$ and then cooled to $4{ }^{\circ} \mathrm{C}$. The amplified $1.5 \mathrm{~kb}$ 16S rDNA (rDNA) fragment was separated by agarose gel electrophoresis. The purified fragment was directly sequenced by using a Taq DyeDeoxy terminator Cycle Sequencing kit (Applied Biosystems) and analysed with an ABI PRISM 377 DNA sequencer (Applied Biosystems). Sequencing primers used included KMSO98PB1r (5' -TAAGGAGGTGATCCAGCC-3'), KMS584P1r (5' TGCTGGCAACACAG AACAAG-3') and KMS584P2r (5' -ACTCTG CCTGCCCGTATCG-3').

Sequence alignment and phylogenetic analysis. The partial $16 \mathrm{~S}$ rDNA sequence of strain YIM $41004^{\mathrm{T}}$ was aligned manually with representative sequences of related streptomycetes from the GenBank database. The evolutionary tree, rooted with Streptomyces megasporus as the outgroup, was inferred by using the neighbourjoining method (Saitou \& Nei, 1987) from the evolutionary distance data corrected by Kimura's two-parameter model (Kimura, 1980). The topology of the resultant tree was evaluated by bootstrap analysis (Felsenstein, 1985) of the neighbour-joining method based on 1000 resamplings. The CLUSTAL X program (Thompson et al., 1997) was used for multiple alignment and phylogenetic analysis. The TreeView program (Page, 1996) was used to display, edit and print phylogenetic trees.

\section{RESULTS AND DISCUSSION}

Morphological observation of the 7-15-day-old culture of strain YIM $41004^{\mathrm{T}}$ grown on yeast extract-malt extract agar (ISP 2) (Shirling \& Gottlieb, 1966) revealed that both aerial and vegetative hyphea were abundant, well-developed and not fragmented; spore chains with many spores were spiral; spores $(0 \cdot 5-1.0 \mu \mathrm{m}$ in diameter) were rugose with short spines and were short pillar-shaped and non-motile (Fig. 1).
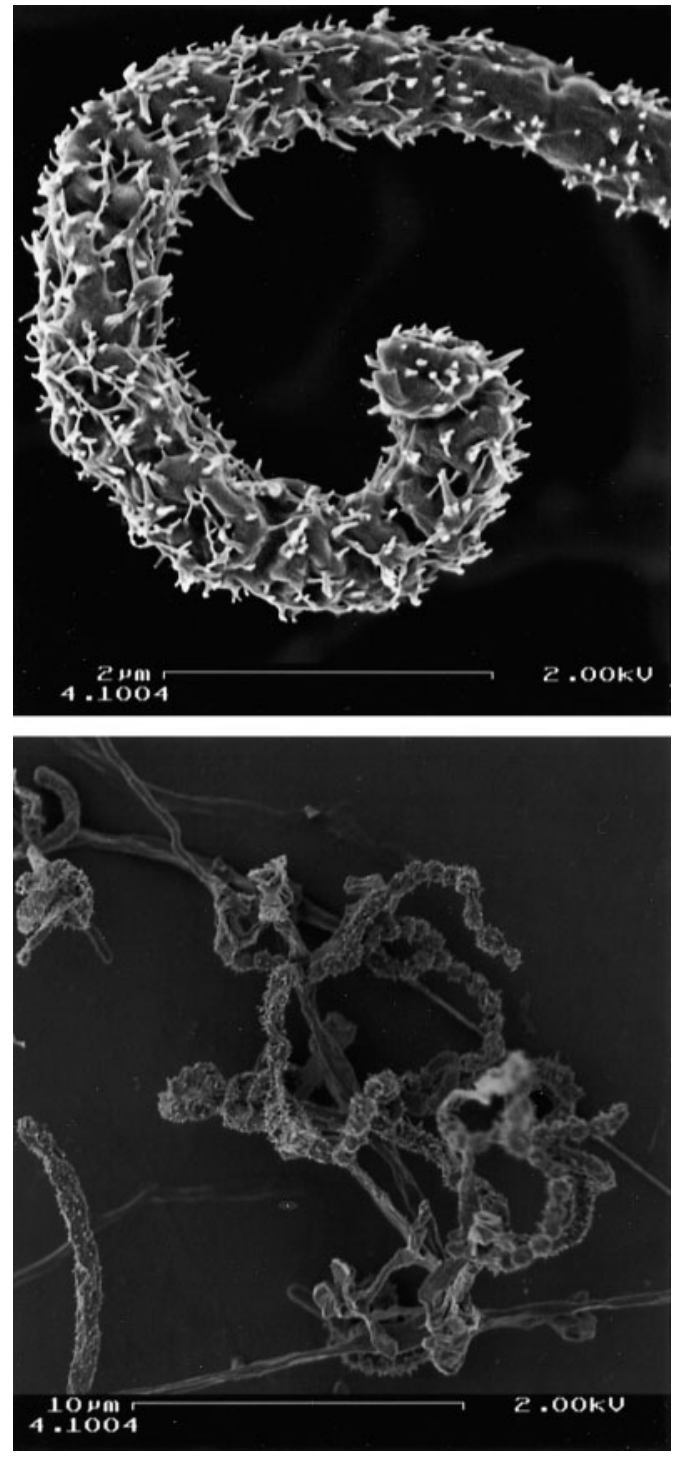

Fig. 1. Scanning electron micrographs showing strain YIM $41004^{\top}$ rugose spores and spiral spore chains (top and bottom) after growth on yeast extract-malt extract agar (ISP 2) at $28^{\circ} \mathrm{C}$ for 15 days.

Table 1. Cultural characteristics of strain YIM $41004^{\top}$

Colours are according to the ISCC-NBS Color Charts Standard Sample No. 2106 (Kelly, 1964).

\begin{tabular}{|llll|}
\hline \multirow{2}{*}{ Agar medium } & \multicolumn{2}{c}{ Colour of mycelium: } & \multirow{2}{*}{ Soluble pigment } \\
\cline { 2 - 3 } & \multicolumn{1}{c}{ Aerial } & \multicolumn{1}{c}{ Substrate } & \\
\hline Czapek's & Light brown-grey & Brown-pink & Absent \\
Glycerol asparagine (ISP 5) & Pale-yellow & Light orange-yellow & Light yellow \\
Inorganic salt-starch (ISP 4) & Light grey-brown & Light grey-yellow & Absent \\
Oatmeal (ISP 3) & Light brown-grey & Light grey-yellow & Absent \\
Yeast extract-malt extract (ISP 2) & Light brown-grey & Light yellow & Absent \\
Glucose asparagine & Light grey-brown & Deep grey-yellow & Absent \\
Potato extract & Brown-grey & Deep grey-yellow & Light yellow \\
\hline
\end{tabular}


Table 2. Physiological characteristics of strain YIM $41004^{\top}$ and related species in the Streptomyces violaceusniger phenotypic cluster

Strains: 1, strain YIM $41004^{\mathrm{T}}$; 2, Streptomyces endus NRRL ISP$5187^{\mathrm{T}}$ (=DSM $\left.40187^{\mathrm{T}}\right)$; 3, Streptomyces hygroscopicus NRRL-ISP $5578^{\mathrm{T}}$ (=DSM $\left.40578^{\mathrm{T}}\right) ; 4$, Streptomyces melanosporofaciens NRRL B-12234 ${ }^{\mathrm{T}}\left(\mathrm{DSM} 40318^{\mathrm{T}}\right) ; 5$, Streptomyces sparsogenes ISP $5356^{\mathrm{T}}$ $\left(=\mathrm{NRRL} 2940^{\mathrm{T}}=\mathrm{DSM} 40356^{\mathrm{T}}\right) ; 6$, Streptomyces violaceusniger NRRL B-1476 ${ }^{\mathrm{T}}\left(=\mathrm{DSM} 41600^{\mathrm{T}}\right)$. + , Positive; -, negative. All strains were negative for milk coagulation and positive for gelatin liquefaction.

\begin{tabular}{|lcccccc|}
\hline Characteristic & $\mathbf{1}$ & $\mathbf{2}$ & $\mathbf{3}$ & $\mathbf{4}$ & $\mathbf{5}$ & $\mathbf{6}$ \\
\hline Milk peptonization & + & + & - & - & + & - \\
Starch hydrolysis & + & + & - & + & - & + \\
Nitrate reduction & - & - & - & - & + & - \\
Urea utilization & + & - & + & - & + & + \\
Carbon source utilization: & & & & & & \\
$\quad$ D-Sucrose & - & + & + & - & + & + \\
$\quad$ D-Xylose & - & + & + & + & + & + \\
$\quad$ D-Raffinose & + & + & + & + & - & + \\
Antimicrobial activity against: & & & & & & \\
$\quad$ Bacillus subtilis & - & - & + & + & + & - \\
$\quad$ Aspergillus niger & + & - & - & + & - & - \\
\hline
\end{tabular}

Cultural characteristics of strain YIM $41004^{\mathrm{T}}$ are shown in Table 1. Aerial mycelium of strain YIM $41004^{\mathrm{T}}$ was abundant, well-developed and varied from light brown-grey to brown-grey on different test media. The substrate hyphae from light yellow to light brown-yellow. Diffusible pigments were not produced on most test media, and melanin was not produced. The cell-wall peptidoglycan of strain YIM $41004^{\mathrm{T}}$ contained only LL-diaminopimelic acid and glycine, indicating that strain YIM $41004^{\mathrm{T}}$ has a chemotype cell-wall type I (Lechevalier \& Lechevalier, 1970a, b). The whole-cell hydrolysates contained galactose.
On the basis of morphological, cultural and chemotaxonomic properties above, together with the physiological properties of strain YIM $41004^{\mathrm{T}}$ and five other related species in Streptomyces violaceusniger phenotypic cluster (Williams et al., 1983, 1989; Labeda \& Lyons, 1991) shown in Table 2, it is evident that strain YIM $41004^{\mathrm{T}}$ not only belongs to the genus Streptomyces but also should be assigned to the Streptomyces violaceusniger cluster (Williams et al., 1983, 1989). Although strain YIM $41004^{\mathrm{T}}$ is similar to members of the Streptomyces violaceusniger cluster and clusters 10, 41, 51, 53, 54 and 85 (Kämpfer et al., 1991) on the basis of phenotypic data, this organism cannot be exactly assigned to any of the known streptomycete species of these clusters on the basis of its phenotypic characteristics. Therefore, it is concluded from phenotypic data that strain YIM $41004^{\mathrm{T}}$ shows no apparent relationship with the validly described species of these clusters (Williams et al., 1983, 1989; Kämpfer et al., 1991). Similarly, strain YIM $41004^{\mathrm{T}}$ is differentiated primarily from four other cycloheximideproducing species based on the surface of spore and carbonsource utilization from Table 3.

The phylogenetic analysis of strain YIM $41004^{\mathrm{T}}$ with members of the Streptomyces violaceusniger cluster (Williams et al., 1983, 1989; Labeda \& Lyons, 1991) reveals that strain YIM $41004^{\mathrm{T}}$ is distinct from species in this cluster, as showed in Fig. 2. The sequence divergence values between strain YIM $41004^{\mathrm{T}}$ and members of the Streptomyces violaceusniger cluster (Williams et al., 1983, 1989; Labeda \& Lyons, 1991) are $2.91 \%$ (S. hygroscopicus), $2 \cdot 70 \%$ (S. melanosporofaciens), $2 \cdot 70 \%$ (S. violaceusniger), $3.27 \%$ (S. sparsogenes), and these indicate that strain YIM $41004^{\mathrm{T}}$ represents a hitherto unpublished species.

The phenotypic and genotypic data of strain YIM $41004^{\mathrm{T}}$ demonstrated that strain YIM $41004^{\mathrm{T}}$ should be given novel species status in the genus Streptomyces Waksman and Henrici $1943^{\mathrm{AL}}$. Therefore, we proposed this organism

Table 3. Partial features for differentiating strain YIM $41004^{\top}$ from cycloheximide-producing species

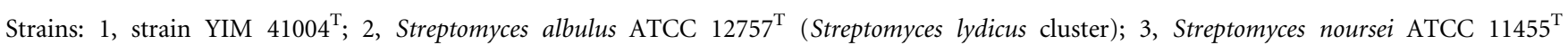
(Streptomyces noursei cluster); 4, Streptomyces griseus ATCC $23345^{\mathrm{T}}$ (Streptomyces anulatus cluster); 5, Streptomyces pulveraceus ATCC $13875^{\mathrm{T}}$ (Streptomyces pulveraceus cluster). Comparative data taken from previous studies (Williams et al., 1983, 1989). +, Positive; -, negative.

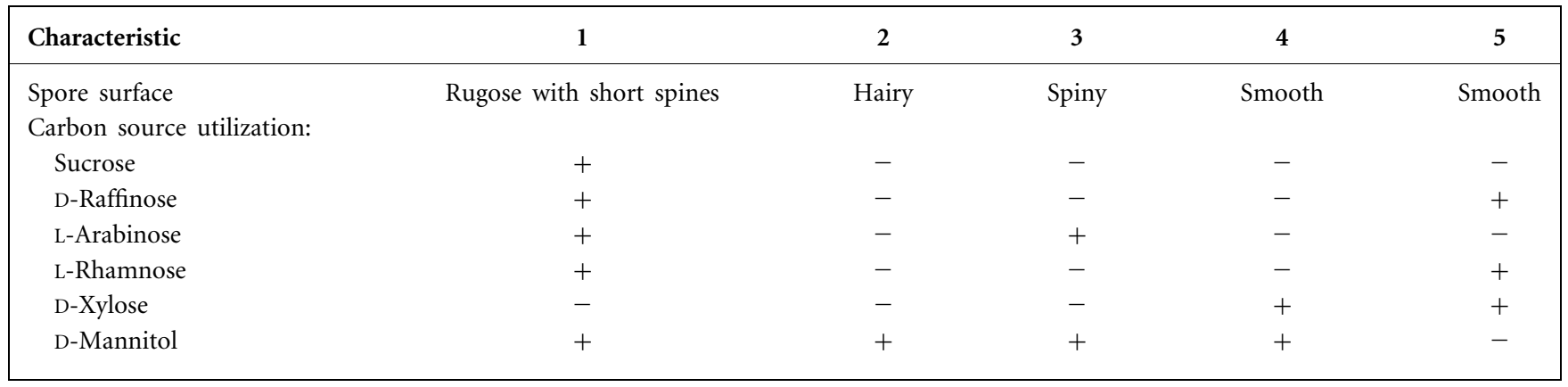




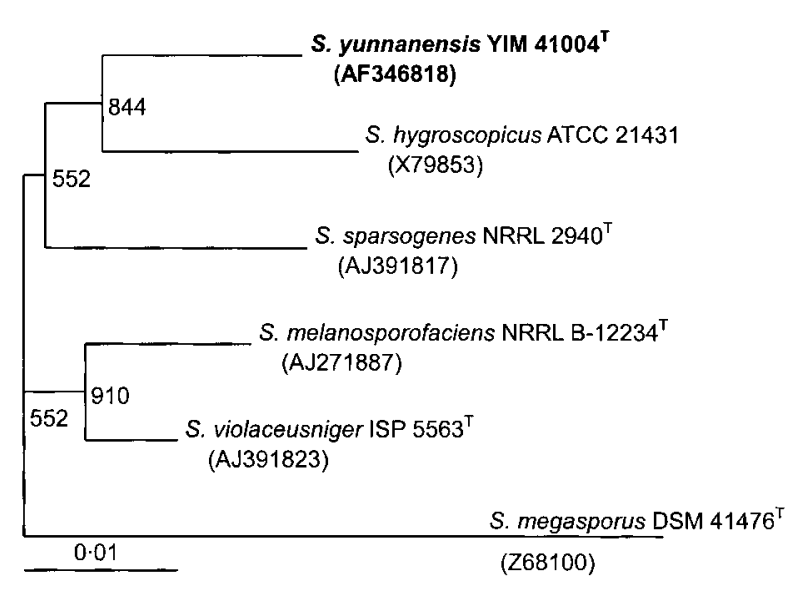

Fig. 2. Neighbour-joining tree (Saitou \& Nei, 1987) showing the phylogenetic relationships among members of the Streptomyces violaceusniger cluster. The analysis included 1453 unambiguous nucleotide positions. Streptomyces megasporus was used as the outgroup. Bootstrap values from 1000 analyses were shown at the nodes of the tree. The scale bar represents one nucleotide substitution per 100 nucleotides of $16 \mathrm{~S}$ rDNA sequence.

should be a new species with the name Streptomyces yunnanensis sp. nov.

\section{Description of Streptomyces yunnanensis sp. nov.}

Streptomyces yunnanensis (yun.nan.en'sis. N.L. masc. adj. yunnanensis pertaining to Yunnan, a province of south-west China).

Both vegetative and aerial hyphae are abundant and welldeveloped. The colour of aerial and substrate mycelium on various solid media is given in Table 1 . Spore chains with many spores are spiral. The spores are rugose with short spines and are short pillar-shaped $(0 \cdot 5-1 \cdot 0 \mu \mathrm{m}$ in diameter) and non-motile. Diffusible pigments are not produced and melanin is not produced. Milk is not coagulated but peptonized, starch is hydrolysed and $\mathrm{H}_{2} \mathrm{~S}$ is not produced. Nitrate is not reduced and gelatin is liquefied. Does not hydrolyse cellulose. Utilizes glucose, fructose, rhamnose, inositol, mannitol, arabinose and raffinose for growth; does not utilize sucrose or xylose. It has antimicrobial activity against Aspergillus niger but not against Bacillus subtilis. Optimum growth is at $28^{\circ} \mathrm{C}$. The cell wall contains LL-diaminopimelic acid and glycine (cell-wall chemotype I). Whole-cell hydrolysates contain galactose. The type strain, YIM $41004^{\mathrm{T}}$, isolated from red soil of the suburb of Kunming in Yunnan, China, was deposited in the China General Microbiological Culture Collection Center (CGMCC) Beijing, China, as strain CGMCC $4.1004^{\mathrm{T}}$, and the DSMZ-Deutsche Sammlung von Mikroorganismen und Zellkulturen $(\mathrm{GmbH})$, Germany, as strain DSM $41793^{\mathrm{T}}$.

\section{ACKNOWLEDGEMENTS}

We are grateful to Dr David P. Labeda for providing some type strains and helping in preparation of this manuscript. This work was supported by the National Natural Science Foundation of China and Funds of the Key Laboratory for Microbial Resources of Ministry of Education, PR China, Yunnan Provincial Commission of Science \& Technology, and The International Cooperation Foundation of Yunnan.

\section{REFERENCES}

Becker, B., Lechevalier, M. P., Gordon, R. E. \& Lechevalier, H. A. (1964). Rapid differentiation between Nocardia and Streptomyces by paper chromatography of whole-cell hydrolysates. Appl Microbiol 12, 421-423.

Brosius, J., Palmer, M. L., Kennedy, J. P. \& Noller, H. P. (1978). Complete nucleotide sequence of a $16 \mathrm{~S}$ ribosomal RNA gene from Escherichia coli. Proc Natl Acad Sci U S A 75, 4801-4805.

Felsenstein, J. (1985). Confidence limits on phylogenies: an approach using the bootstrap. Evolution 39, 783-791.

Hopwood, D. A., Bill, M. J., Charter, K. F. \& 7 other authors (1985). Genetic Manipulation of Streptomycetes: a Laboratory Manual. Norwich: John Innes Foundation.

Kämpfer, P., Kroppenstedt, R. M. \& Dott, W. (1991). A numerical classification of the genera Streptomyces and Streptoverticillium using miniaturized physiological tests. J Gen Microbiol 137, 1831-1891.

Kelly, K. L. (1964). Inter-Society Color Council-National Bureau of Standards Color-Name Charts Illustrated with Centroid Colors. Washington, DC: US Government Printing Office.

Kimura, M. (1980). A simple method for estimating evolutionary rates of base substitutions through comparative studies of nucleotide sequences. J Mol Evol 16, 111-120.

Labeda, D. P. \& Lyons, A. J. (1991). The Streptomyces violaceiniger cluster is heterogeneous in DNA relatedness among strains: emendation of the descriptions of S. violaceiniger and Streptomyces hygroscopicus. Int J Syst Bacteriol 41, 398-401.

Lechevalier, H. A. \& Lechevalier, M. P. (1970a). A critical evaluation of the genera of aerobic actinomycetes. In The Actinomycetes, pp. 393-405. Edited by H. Prauser. Jena: Gustav Fischer Verlag.

Lechevalier, M. P. \& Lechevalier, H. A. (1970b). Chemical composition as a criterion in the classification of aerobic actinomycetes. Int J Syst Bacteriol 20, 435-443.

Lechevalier, M. P. \& Lechevalier, H. A. (1980). The chemotaxonomy of actinomycetes. In Actinomycete Taxonomy, pp. 22-291. Edited by A. Dietz \& D. W. Thayer. Arlington, VA: Society for Industrial Microbiology.

Page, R. D. M. (1996). TREEVIEW: an application to display phylogenetic trees on personal computers. Comput Appl Biosci 12, 357-358.

Saitou, N. \& Nei, M. (1987). The neighbor-joining method: a new method for reconstucting phylogenetic trees. Mol Biol Evol 4, 406425.

Shirling, E. B. \& Gottlieb, D. (1966). Methods for characterization of Streptomyces species. Int J Syst Bacteriol 16, 313-340.

Thompson, J. D., Gibson, T. J., Plewniak, F., Jeanmougin, F. \& Higgins, D. G. (1997). The Clustal X windows interface: flexible 
strategies for multiple sequence alignment aided by quality analysis tools. Nucleic Acids Res 24, 4876-4882.

Williams, S. T., Goodfellow, M., Alderson, G., Wellington, E. M. H., Sneath, P. H. A. \& Sackin, M. J. (1983). Numerical classification of Streptomyces and related genera. J Gen Microbiol 129, 1743-1813.
Williams, S. T., Goodfellow, M. \& Alderson, G. (1989). Genus Streptomyces Waksman and Henrici 1943, 339 ${ }^{\mathrm{AL}}$, pp. 2452-2492. In Bergey's Manual of Systematic Bacteriology, vol. 4. Edited by S. T. Williams \& M. E. Sharpe. Baltimore: Williams \& Wilkins. 